The Strength of Knowledge

in Plato's Protagoras (355a-358d)

Justin C. Clark

Writing Sample 


\section{The Strength of Knowledge in Plato's Protagoras}

During a discussion about the unity of virtue, Socrates begins questioning Protagoras about his attitude toward knowledge, to see whether he agrees with the Many concerning this. The Many contend that knowledge is something weak, and that it often gets dragged around by other things (anger, pleasure, love and fear). But Socrates and Protagoras hold that the Many are wrong; they undertake to defend the following thesis against the Many:

(KS) knowledge is something strong and ruling, which cannot be overcome by pleasure (352b).

This thesis introduces an apparent digression, as Socrates begins to discuss the phenomenon of moral weakness. Often, a man who knows which action is best chooses nevertheless to perform a different action instead. This is the description we are given of weakness, and the Many

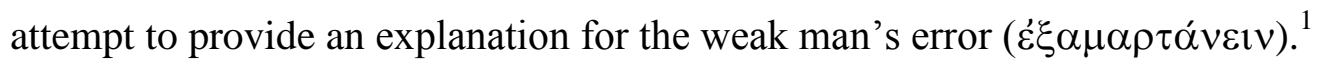

(E) often a man knows $\phi$ to be bad, yet nevertheless he performs $\phi$ willingly because he is defeated by pleasures (352d).

In response, Socrates seeks to clarify the prevailing attitude toward pleasure, which turns out to be entirely hedonistic. Initially, it had appeared as though the Many held a modest view of pleasure, that some pleasures are good and others are bad. But upon further inspection, Socrates and Protagoras discover that the Many regard certain pleasures as bad, only because they eventually produce long-term pain (e.g. poverty, sickness, etc.). And similarly, they regard certain pains as good, only because they eventually produce long-term pleasure. The Many,

\footnotetext{
${ }^{1}$ To be more precise about the description of weakness in our dialogue, it is part of the description that the weak

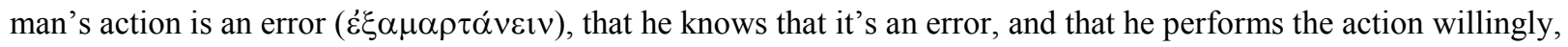

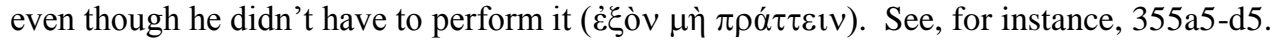


therefore, have no other criterion of goodness than pleasure, and no other criterion of badness than pain. They are committed to ethical hedonism:

(H) : (Ha) All pleasure (qua pleasure) is good (353e), and (Hb) All good is pleasure; there is no other criterion of goodness $(354 \mathrm{e})$.

But once hedonism $(\mathrm{H})$ is secured from the Many, Socrates informs them that, when taken together with hedonism, their previous explanation of weakness (E) becomes ridiculous

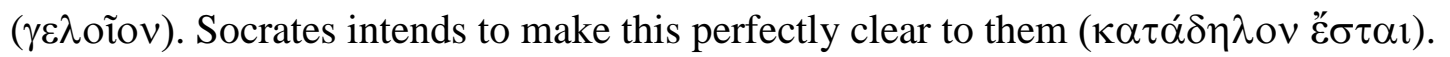
Unfortunately, the demonstration he provides is anything but clear. At one point in the text (358c), Socrates introduces his intellectualist thesis (no one errs willingly), which brings to mind (quite naturally, given the context) the principle of psychological hedonism ${ }^{2}$ :

(PH) necessarily, men must always choose the action they think most pleasant (358dc).

Of course, the introduction of psychological hedonism complicates things. If Socrates is relying on $(\mathrm{PH})$ during the demonstration, then he is probably begging the question against the phenomenon of weakness.

Commentators have tied themselves in knots trying to understand this portion of the Protagoras. It has been described as an argument of "labyrinthine complexity, densely concentrated, elliptical at crucial points, yet presented with an air of conviction that marks it as

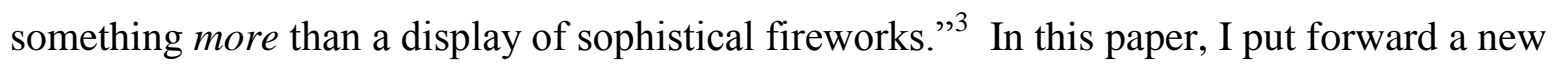
interpretation of Socrates' argument - a modified version of (what I call) the epistemic

\footnotetext{
${ }^{2}$ Under the assumption of ethical hedonism $(\mathrm{H})$, where pleasure is the only good, the intellectualist thesis seems to imply psychological hedonism (PH). If people regard pleasure as the only good, and people always do what they think is best, it follows that people always do what they think is most pleasant. So, Socrates introduces (PH) alongside the intellectualist thesis (356b).

${ }^{3}$ Gallop (1964), p.1-2
} 
interpretation. On the epistemic interpretation, (E) is ridiculous because it attributes knowledge to an agent while also claiming that he has no such knowledge. Gallop's (1964) original epistemic interpretation employs both the intellectualist thesis and psychological hedonism to establish the contradiction. In fact, most interpretations assume that these principles are operative. ${ }^{4}$ I depart from the majority of commentators, and from Gallop, by arguing that Socrates does not employ intellectualism or psychological hedonism $(\mathrm{PH})$ in his refutation of the Many. Socrates employs a form of psychological eudaemonism. This makes more sense of the argumentative details. If correct, my interpretation will challenge the notion that the passage amounts to a 'Socratic denial of akrasia.' It will establish instead that it is merely an argument for the strength of knowledge (KS) ${ }^{-5}$ After providing a brief overview of the argument (section II), I will reject a competing interpretation (section III) and then make the necessary modifications to the epistemic interpretation (section IV).

\section{Neutral Overview of Socrates’' Argument (355a - 358d)}

At 355a, Socrates begins his argument against the Many. He undertakes to show that, on the assumption of ethical hedonism $(\mathrm{H})$, their explanation of weakness $(\mathrm{E})$ becomes ridiculous $\left(\gamma \varepsilon \lambda \circ\right.$ oĩov). ${ }^{6}$ Even further than this, Socrates undertakes to demonstrate what the experience

\footnotetext{
${ }^{4}$ Wolfsdorf (2006), Penner (1991), Weiss (1990), Klosko (1980), Gallop (1964), Vlastos (1969), Santas (1966). Only Dyson (1976) takes a stance against this.

${ }^{5}$ The modern understanding of akrasia involves acting contrary to what one believes to be best. However, Socrates' argument denies the possibility only of acting contrary to what one knows to be best, since knowledge is something strong and ruling.

6 Socrates' demonstration takes the form of a reductio, but as we shall see, there is much debate over the type of absurdity (E) is reduced to. This is the interpretive problem with which I will be concerned. Another interpretive problem concerns the identification of pleasure with good $(\mathrm{H})$, which is essential to Socrates' demonstration, but appears to be wholly out of tune with his moral outlook. Considering its central role in the dialogue, commentators have wondered whether $(\mathrm{H})$ represents Socrates' own position, or whether it is merely adopted ad hominem against his interlocutors. I cannot deal with the issue in any detail, but let me say a few words. Socrates uses one belief of
} 
( $\pi \dot{\alpha} \theta$ os) of being overcome by pleasure really is. His method is to exploit the identification of pleasure with good, and pain with bad, implicit in the hedonism (H) of the Many.

"The ridiculousness of this [explanation] will become clear if we stop using all these names togetherpleasant, painful, good, and bad - and since they have turned out to be only two, call them by only two names - first of all good and bad, and after that, pleasure and pain.” (355a-b)

Socrates means to apply two substitutions to the explanation (E). In the first substitution, he will replace 'pleasures' with 'goods.' And on the second substitution, he will replace 'bad' with 'painful.' The explanation, upon the first substitution, becomes the following:

(Eg) often a man knows $\phi$ to be bad, yet nevertheless he performs $\phi$ willingly because he is defeated by goods $(355 \mathrm{c})$.

At $355 \mathrm{c}$, Socrates claims that an arrogant questioner will laugh at (Eg), and say that it is ridiculous ( $\gamma \varepsilon \lambda \mathrm{oĩov})$. What precisely the arrogant questioner finds ridiculous, however, remains unclear. Socrates never elaborates. He simply begins to analyze the explanation. By description of the case, the weak man knows which of the available actions is best; yet he performs a worse action instead. In fact, he performs a bad action, knowing that it is bad. And the Many allege that he commits this error because he has been "defeated ( $\dot{\eta} \tau \dot{\omega} \mu \varepsilon v \circ)$ by

the Many $(\mathrm{H})$ to reveal an inconsistency with another belief of the Many (E). As a result, the passage has been recognized as "a perfect example of Socrates' favorite mode argument, displaying the overall structure of an elenchus." Like any instance of the elenchus, Socrates need not accept the required premise $(\mathrm{H})$, nor need he reject it. And there seems to be very little evidence either way in the Protagoras. Thus, conclusions about Socrates' personal attitude toward $(\mathrm{H})$ are often reached externally by reference to other dialogues. Although it has been argued that (H) showcases a more generous view of pleasure than the view under assault in later dialogues (Gorgias and Republic), I agree with those commentators point to a startling contrast from the Phaedo, where practical reason does not aid the maximization of pleasure (as it does in the Protagoras). Practical reason is depicted there as a rival to the hedonistic calculus; and the philosopher is depicted as one who pursues practical wisdom ( $\phi \rho o ́ v \eta \sigma ı)$ instead of the maximization of pleasure. In the Protagoras, Socrates contents himself with a (single) widely-recognized good- pleasure. Once he does this, he is able to demonstrate the unparalleled importance of knowledge to the good life. Just as in the Laches and Charmides, we are given a conception of virtue as "the knowledge of good and bad." Yet, only in the Protagoras does Socrates manage to provide an approximation of how that knowledge might look. By restricting the present discourse to a "shared zone of moral choice," he manages to offer a limited portrait of the knowledge that is virtue. 
goods." Yet, the goods by which he has been defeated are not worthy (oúк $\alpha \dot{\xi} i \omega v$ ) of the victory. ${ }^{7}$ This can only mean that the weak man's action $\phi$ contains both good and bad consequences, where the bad consequences outweigh the good. Thus, the questioner infers that the weak man knowingly accepts ( $\lambda \alpha \mu \beta \alpha ́ v \varepsilon \imath v)$ greater evils as the price for securing ( $\dot{\alpha} v \tau i ́)$ lesser goods. ${ }^{8}$ We should acknowledge that the explanation sounds rather strange. We might wonder, for instance, what it means for someone to be "defeated by goods" which are outweighed by evils. But without further elaboration, Socrates continues with the second substitution. The explanation, upon the second substitution, becomes the following:

(Ep) often a man knows $\phi$ to be painful, yet nevertheless he performs $\phi$ willingly because he is defeated by pleasures.

Again, the weak man has performed an action $\phi$ that produces both pleasures and pains. But the pleasures by which he is defeated are, by hypothesis, not worthy (oúк $\dot{\alpha} \xi i \omega v$ ) of the victory. His action is painful on the whole. This can only mean that the pleasures are smaller (fewer, or less intense) than the pains attending the action, so that the pains outweigh the pleasures. Of course, once hedonism $(\mathrm{H})$ has been assumed, the value of an action must be determined solely

\footnotetext{
${ }^{7}$ Concerning the role of this adjective-- $\dot{\alpha} \xi \hat{i} \omega v$. It is unclear what exactly it means for someone to ask (as the arrogant questioner does at 355d) whether the goods are worthy of conquering the bads, or vice versa. Vlastos (1969) was first to observe that $\dot{\alpha} \xi \hat{\xi} \omega v$ is a value-term. $\dot{\alpha} \xi \hat{i} \omega v$ implies that the goods and bads have a certain value. Thus, the questioner is asking whether the goods (i.e. the pleasures) by which our man is defeated are superior to the bads (i.e. pains), which also accompany the action. Yet, since the weak man's action is an error, the goods are no match for the bads.

${ }^{8}$ The verb $\lambda \alpha \mu \beta \alpha ́ v \varepsilon ı v$ and the particle $\alpha \nu \tau \iota$ have also been cause for controversy. At $355 \mathrm{e} 2$, the weak man is said

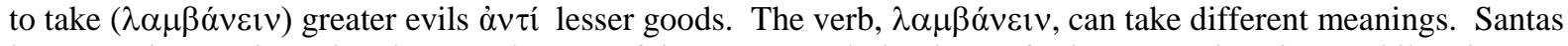
interprets it as an intentional act on the part of the agent, rendering it "preferring," or "choosing," while other interpreters follow a more common reading, e.g. "taking," "accepting." The particle is perhaps even trickier. The most common way of rendering $\alpha \nu \tau \imath$ is to render it "instead of" or "in exchange for," but Gallop (1964) has made the important observation that these translations imply that the agent has not taken the goods along with the bads. Thus, many commentators agree that $\dot{\alpha} v \tau i$ should be rendered "in return for securing." Much of this discovery goes to J.L. Stokes (1913), who first perceived a solution to the interpretive puzzle. In his (1913) he suggested that "goods" and "bads" should not be understood as alternative courses of actions, but rather as consequences (or effects) of a single course of action.
} 
by the sum quantity of pleasures over pains. With that said, however, some pleasures are experienced more immediately than others, some more (temporally) remote. And Socrates readily acknowledges this (356a5). But since the nearness or remoteness of a pleasure cannot affect its actual size, Socrates insists that such temporal distance cannot affect the overall value of an action.

Now according to (Ep), the weak man knows the values of the actions available to him. So what could possibly motivate him to choose a bad action? Socrates thinks he can explain. Although the nearness or remoteness of a pleasure cannot affect its actual size, the nearness or remoteness of a pleasure can affect its apparent size (356c). Just as visible objects appear larger when closer in proximity to the observer, pleasures and pains appear greater when (temporally)

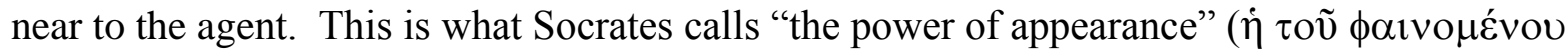
$\delta u ́ v \alpha \mu \imath \varsigma)$. Its illusory affect often causes confusion in the moral agent. Thus, to avoid a miscalculation of value, the agent must counteract this appearance. He must place each pleasure and each pain in the same scale, regardless of temporal distance, and establish whether the painful consequences outweigh the pleasurable, or vice versa (356b). In other words, the moral agent must develop an expertise - the skill of measuring relative quantities of pleasures and

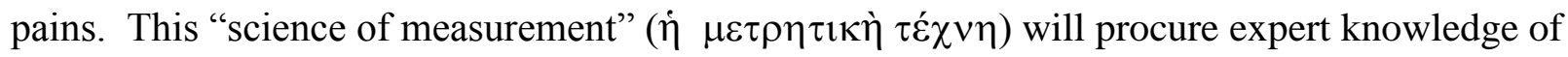
the overall value of any given action.

According to Socrates, provided that hedonism $(\mathrm{H})$ is true, such knowledge turns out to be our salvation in life ( $\sigma \omega \tau \eta \rho i ́ \alpha)$, since the power of appearance will no longer cause the man who has it to waver in his judgment concerning what to do. ${ }^{9}$ Being "defeated by pleasures" is

\footnotetext{
${ }^{9}$ Socrates suggests that the power of appearance will cause one to vacillate, or to "waver up and down concerning the same things."356D4
} 
then equated with being confused or swayed by the illusory power of appearance. One who is swayed by the power of appearance is swayed because he lacks the science of measurement. Thus, being defeated by pleasures is merely a form of ignorance- what Socrates calls "the greatest ignorance." At 357e, having secured these points, Socrates now reminds the hypothetical Many that, although they would have laughed at such a conclusion initially, they

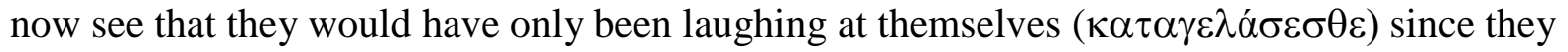
really agree that being 'defeated by pleasure' is nothing more than ignorance.

Finally, at 358a, Socrates turns his attention back to the Sophists. Addressing the Sophists, he secures agreement to the explanation just offered, and subsequently expresses the principle of psychological hedonism.

"If then, the pleasant is good, no one who either knows or believes that there is another possible course of action, better than the one he is following, will ever continue on his present course of action when he might choose the better." (358 b-c)

At this point, Socrates defines ignorance as "having a false opinion ( $\tau$ ò $\psi \varepsilon v \delta \tilde{\eta}$ " $\chi \varepsilon \imath v \delta o ́ \xi \alpha v)$ and being mistaken in matters of great moment." Once he establishes these details, he immediately expresses his intellectualist thesis that no one errs willingly.

"Then it must follow that no one willingly goes for bad things or things he believes to be bad. To make for what one believes to be bad, instead of making for the good, is not, it seems, in human nature, and when faced with the choice between two evils no one will choose the greater when he might choose the less." $(358 \mathrm{c}-\mathrm{d})$

The intellectualist thesis is introduced here (alongside psychological hedonism) as a conclusion, but subsequently employed in an argument against Protagoras' initial claim, which says that courage is different from the other virtues (wisdom, piety, justice and temperance). The demonstration is complex. As we shall see, it involves many pitfalls that require attention. 


\section{What's so Ridiculous?}

Commentators disagree about where the ridiculousness of $(\mathrm{E})$ is made clear in the text

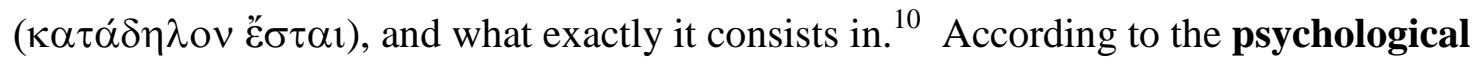
impossibility interpretation, explanation $(\mathrm{E})$ is ridiculous because it reduces to the claim that men often do what cannot be done. More specifically, (E) suggests that men often perform a psychologically impossible task. Socrates' argument is structured so as to include psychological hedonism $(\mathrm{PH})$ - the most controversial component of the interpretation. It is alleged that, in addition to ethical hedonism $(\mathrm{H})$, psychological hedonism $(\mathrm{PH})$ plays a significant role in Socrates' argument. In other words, the argument assumes that all voluntary action is aimed at achieving pleasure, and that no one can knowingly accept ( $\lambda \alpha \mu \beta \alpha ́ v \varepsilon \imath v)$ the lesser of two available pleasures. This is inconsistent with the explanation (E) offered by the Many, which states that men often knowingly and willingly perform the inferior (or less pleasant) action because they are defeated by pleasures. ${ }^{11}$

\footnotetext{
${ }^{10}$ Dyson provides an interpretation worth noting. He suggests that the ridiculousness of (E) is nothing very technical, just an immediate fatuousness, or silliness. In other words, (E) is supposed to appear silly upon the first substitution, no later than 355c. I agree in part. However, this interpretation is incomplete. Socrates says the ridiculousness of (E) will become clear "if we stop using many names together," and instead use one pair of names at a time. It is made explicit that, since there are two pairs of names, Socrates will employ two separate substitutions in order to make this clear. For us to suppose the ridiculousness of (E) to be fully demonstrated already after the first substitution would require us to overlook the plan Socrates laid down.

${ }^{11}$ Different versions of this interpretation have been offered by Santas (1966) and Vlastos (1969). On either account, the Many are said to have given an explanation which contains a psychological impossibility due to the inclusion of (PH). On Santas" account, $\lambda \alpha \mu \beta \alpha$ óviv is taken in the sense of "preferring," or "choosing," so that (PH) contradicts the explanation (E) because it is impossible to knowingly prefer the lesser of two available actions. Vlastos, on the other hand, assumes that two additional Socratic principles are operative in the demonstration: (S1) If one knows that $\mathrm{X}$ is better than $\mathrm{Y}$, one will want $\mathrm{X}$ more than $\mathrm{Y}$, and (S2) If one wants $\mathrm{X}$ more than $\mathrm{Y}$, one will choose $\mathrm{X}$ rather than $\mathrm{Y}$. These principles are never stated in the demonstration, but Vlastos thinks that they are operative nevertheless. Moreover, these principles are derived from psychological hedonism $(\mathrm{PH})$, which directly conflicts with explanation (E) of the Many.
} 
This interpretation can only be made tenable by strong evidence of $(\mathrm{PH})$ within the argument. Three distinct passages have been offered as evidence. As early as 354c, during an attempt to clarify the prevailing attitude toward pleasure, Socrates secures agreement to the statement that the Many "pursue ( $\delta 1 \omega ́ \kappa \varepsilon \tau \varepsilon)$ pleasure as good, and flee ( $\phi \varepsilon u ́ \gamma \varepsilon \tau \varepsilon)$ pain as bad." Now, this statement certainly doesn't exclude psychological hedonism; it could even be asserted within the context of psychological hedonism. But it cannot serve as evidence here in favor of $(\mathrm{PH})$ over $(\mathrm{H})$ - i.e. we have no reason to treat it as an expression of psychological hedonism rather than ethical hedonism. In fact, the context plainly indicates that the passage expresses the values of the Many. The Many have no other criterion of goodness than pleasure, $(\mathrm{Hb})$. Most commentators agree, therefore, that this is "a claim about their ethics in practice."12

A more convincing passage occurs at 356b-c. This passage takes place after the second substitution, and within the context of the science of measurement. It contains three verbal

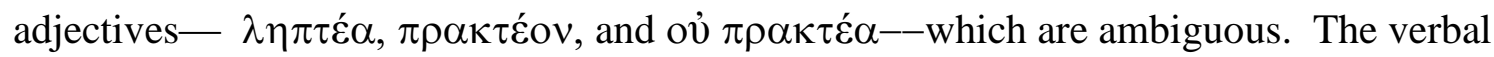
adjectives could be rendered 'must' or simply 'ought to.' At 356b, Socrates is explaining how the good man assesses pleasurable and painful consequences, placing them together in the same scale, regardless of temporal distance. It is unclear, however, whether Socrates intends to say that one must choose the action deemed most pleasant overall (i.e. psychological hedonism), or simply that one should choose the action deemed most pleasant overall. In other words, we must decide whether the passage constitutes a descriptive claim about what must be done (of psychological necessity), or a prescriptive claim about what ought to be done (by prudential obligation).

\footnotetext{
${ }^{12}$ See Dyson (1976) p.33
} 
In order to make an intelligent decision on this score, it is necessary to pay special attention to the context in which the verbal adjectives occur. The verbal adjectives follow an imperative, $\varepsilon i \grave{\imath} \dot{\varepsilon}$, "to say." Socrates has advised us that, much like an expert measurer, we should place the pleasures and pains together in the same scale. Moments later, he implores us to "say ( $\varepsilon i \pi \dot{\varepsilon})$ which of the two is greater" (356b2). Only then do we get the verbal adjectives. Given the imperative, commentators have reasoned that the verbal adjectives are more naturally read as gerundives, specifying what ought to be done. Or that the imperative signals a recommended procedure- one which ought to be followed. ${ }^{13}$ Along similar lines, it has been observed that, since there is no clear statement of psychological hedonism in the immediate neighborhood prior to the use of the verbal adjectives, the Many (against whom Socrates is presently arguing) could not reasonably be expected to understand the verbal adjectives as implying anything other than a prudential obligation. ${ }^{14}$ These observations pose problems for the psychological necessity interpretation; and these problems are only intensified by other features of the context. For example, the verbal adjectives occur within the second substitution, parallel to the first, where the arrogant questioner had pointed out that the goods by which the weak man is defeated are not worthy ( $\dot{\alpha} \xi \dot{i} \omega v)$ of the victory. The value-term here, $\dot{\alpha} \xi \hat{\imath} \omega v$, reappears after the second substitution. At 356a, Socrates says that the pleasures by which our man is defeated are not worthy ( $\dot{\alpha} \xi \hat{\imath} \omega v)$ of the victory. Commentators have pointed out that, in the context of choice, $\dot{\alpha} \xi \hat{i} \omega v$ naturally implies a prudential obligation, since an action that contains pleasures worthy of

\footnotetext{
${ }^{13}$ Wolfsorf has correctly noted that the imperative here is "perfectly compatible" with either the psychological necessity or the prudential obligation. However, while the imperative is compatible with either interpretation, it is much more natural to take it as signaling a prudential obligation. See also D. Wolfsdorf (2006).

${ }^{14}$ Wolfsdorf (2006) pg. 125
} 
victory ought therefore to be chosen ( $\lambda \alpha \mu \beta \alpha$ óvevv). And so, an examination of the immediate context appears to condemn the psychological necessity interpretation. ${ }^{15}$

Some commentators have adopted the psychological necessity interpretation nonetheless. Their insistence is, in large part, a consequence of our third passage, often seen as evidence that (PH) factors into the demonstration. At 358c, after Socrates has reached his conclusion that being overcome by pleasure is merely ignorance, he introduces $(\mathrm{PH})$ alongside his intellectualist thesis that 'no one errs willingly.'

\begin{abstract}
"Then it must follow that no one willingly goes for bad things or things he believes to be bad. To make for what one believes to be bad, instead of making for the good, is not, it seems, in human nature, and when faced with the choice between two evils no one will choose the greater when he might choose the less." $(358 \mathrm{c}-\mathrm{d})$
\end{abstract}

This is the clearest formulation of $(\mathrm{PH})$ in the dialogue. And so, even despite the fact that 'ought' is the more natural reading of the verbal adjectives, commentators have argued that $(\mathrm{PH})$ is surely intended, since the intellectualist thesis features prominently in the discussion after Socrates' explanation of weakness, and is accompanied by (PH) ${ }^{16}$ After all, Socrates unequivocally refers to human nature. He argues that it is not possible (given human nature) to choose the greater of two available evils. In a context where pleasure is the only recognized good, and pain is the only recognized evil, this statement clearly invokes (PH).

\footnotetext{
${ }^{15}$ In further support of this, it has been documented that nearly every occurrence of these verbal adjectives in Plato

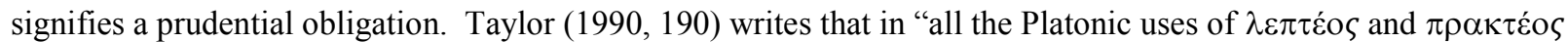
recorded by Ast., the context is one where a course of action is recommended." Brandwood cites two instances of $\lambda \eta \pi \tau \varepsilon_{0} v$ (Phileb. 34 d2, 61 a5) and six instances of $\pi \rho \alpha \kappa \tau \varepsilon o v$ (Crito 46 b3, 47 b9; Grg. 499 e4, 506 c8; Rep 457). Each of these instances speak against a psychological necessity reading. There is one possible exception. Wolfsdorf (2006) has shown that the passage at Grg. 499 e1-7 suggests a psychological necessity using the verb $\pi \rho \alpha \kappa \tau \varepsilon$ ćv. And so, while there is some evidence outside of the Protagoras for using these verbal adjectives for psychological necessity, it is very minimal.

${ }^{16}$ See footnote 2
} 
But there are problems for this passage as well. The passage occurs at such an extremely late stage in Socrates' demonstration that it cannot reasonably be thought to constitute a major premise in his argument against (E). Here, psychological hedonism $(\mathrm{PH})$ appears as more of a "corollary to the conclusion that wrongdoing is ignorance" than a major premise in the argument establishing the ridiculousness of (E). ${ }^{17}$ Along these lines, one cannot be expected to take the intellectualist thesis, tagged haphazardly on to the end of an argument, and run it backwards through the argument to which it is conjoined. I believe this objection, first formulated by Dyson, can gain further support from another observation which has not yet found a place in the literature. Consider the following observation.

Socrates begins addressing the Many at 352d, where he extends his invitation to Protagoras, saying "Come, attempt with me to persuade the Many and to teach them what this experience is..." at which point the dialogue with the Many ensues. The dialogue continues until 358a, where Socrates finally brings it to an end, saying “...these are the answers we would have given to the Many." At 358a, then, the conversation with the Many is over. Socrates turns his attention back to Hippias, Prodicus and Protagoras, three of the Sophists present in the audience. Directing his words toward them, he asks "Hippias and Proticus, along with Protagoras-for you too may share in the discussion - is what I am saying true or false in your opinion?" It is only after Socrates has ceased to address the Many, and has begun to address the Sophists, that he formulates his intellectualist thesis, resulting in the passage above (358c-d). I suggest that it is implausible that the intellectualist thesis and the articulation of $(\mathrm{PH})$ would factor into the argument against the Many, when the conversation with the Many has already ended. Those who endorse the psychological necessity interpretation will have a hard time explaining why

\footnotetext{
${ }^{17}$ Dyson (1976), pg. 33
} 
Socrates expresses such a crucial premise only after the argument has ended, and only after Socrates' respondent has changed. Nor should our passage be taken to inform the verbal adjectives of $358 \mathrm{~b}$, since Socrates has (in the meantime) shifted his attention from the Many to the Sophists. Socrates had previously used the verbal adjectives (358b) while demonstrating to the Many that their explanation (E) was ridiculous; yet he articulates psychological hedonism (358c-d) while addressing the Sophists only after the dialogue with the Many has ended. Placed alongside the previous evidence, this observation has led me to reject the psychological necessity interpretation.

The epistemic interpretation, however, provides another possible account of the ridiculousness of (E). According to this interpretation, (E) is ridiculous because it attributes knowledge to an agent, while also claiming that he has no such knowledge. (The weak man knows what's best, but performs a different action willingly, because he doesn't know what's best). In this case, the ridiculousness of (E) is made clear around 357d, upon the second substitution, where Socrates demonstrates that being defeated by pleasure is merely a lack of knowledge. The end result is that (E) reduces to the claim that a man performs an action, knowing it to contain more pain than pleasure, because he does not know it to contain more pain than pleasure. In order to uncover this contradiction, Gallop has suggested that we think of (E) as a compound assertion involving two separate claims, (Ea) and (Eb):

(E): (Ea) the weak man knows $\phi$ to be bad, yet nevertheless (Eb) he performs $\phi$ willingly because he is overcome by pleasures.

According to Gallop, Socrates argues (using the two substitutions) that (Eb) entails the denial of

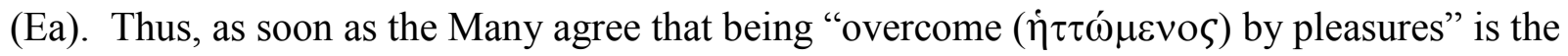
same thing as not knowing the value of an action, the logical contradiction has emerged. By 
asserting (E), the Many have inconsistently attributed both knowledge (concerning the value of $\phi$ ) and ignorance (concerning the value of $\phi$ ) to the weak man. This contradiction is never made explicit in the text, but it can be drawn from the text without too much interpretive strain, and it makes the ridiculousness of (E) much more palpable. That being said, however, the epistemic interpretation does require that a connection be established between error and ignorance. In other words, it must be explained how $(\mathrm{Eb})$ entails the denial of (Ea). (Incidentally, this will require an explanation of how being "overcome by pleasure" is the same thing as not knowing the value of an action.) And Gallop establishes this entailment by invoking psychological hedonism (PH). According to Gallop,

\footnotetext{
"when Socrates claims that we should be saved by the art of measurement, he is assuming that if only we had such an art we should unquestionably apply it in any given situation, and act in accordance with the results it yielded."
}

For Gallop, the key to Socrates' argument is psychological hedonism (PH). But a few problems emerge from this suggestion. First, we have already observed that the context did not favor the inclusion of $(\mathrm{PH})$. Second, for Socrates to claim that men always act in accordance with the results of their measurements, or that men must necessarily choose the action they judge most pleasant overall, is simply to beg the question against the phenomenon ( $\pi \alpha \dot{\theta} \circ \varsigma)$ being explained. ${ }^{18}$ In other words, the inclusion of (PH) makes for a bad argument. And finally, if we allow that $(\mathrm{PH})$ plays a significant role in the argument against $(\mathrm{E})$, then the ridiculousness of $(\mathrm{E})$

\footnotetext{
${ }^{18}$ Presumably, this is why the present argument is often mistakenly portrayed as the denial of akrasia, and not as an argument for the strength of knowledge (KS). Socrates makes it quite clear that he is arguing not against the phenomenon of weakness, but against the explanation of it (E). Also, the modern conception of akrasia involves acting against one's belief about what's best, but he does not speak of belief until after the argument with the Many has ended. He is concerned with the strength of knowledge (KS).
} 
will have been explicable already by means of the psychological necessity interpretation. In this case, there would be no need to advance the epistemic interpretation. ${ }^{19}$

\section{Modifying the Epistemic Interpretation}

Commentators have typically assumed that the epistemic interpretation requires psychological hedonism to establish the connection between error and ignorance, that $(\mathrm{PH})$ is required to explain how (Eb) entails the denial of (Ea). However, it may be worthwhile to explore the text for another possibility. Perhaps the entailment can be established without psychological hedonism (PH). In this section, I propose a version of the epistemic interpretation which does not invoke $(\mathrm{PH})$. I maintain that $(\mathrm{E})$ is ridiculous because it attributes knowledge to an agent while also claiming that he has no such knowledge, and that the knowledge in question concerns pleasures and pains, good and bad. However, we might notice that Plato never puts the relevant knowledge exclusively in terms of actions or consequences. The knowledge attributed to the weak man is described generally as the knowledge "of bad things that they are bad." 20 Thus, we ought to think of (E) as the following compound assertion:

(E): (Ea*) the weak man knows of bad things that they are bad, yet nevertheless (Eb) he performs a bad action $\phi$ willingly because he is overcome by pleasures.

Of course, if our man knows of bad things that they are bad, then he knows of $\phi$ that it is a bad action. Yet, according to (E), he performs $\phi$ because he is overcome by pleasure. We have seen

\footnotetext{
${ }^{19}$ Even if the epistemic interpretation gains explicitness over the psychological necessity interpretation (which seems correct to me) the interpretation will be rendered somewhat gratuitous.

${ }^{20}$ It is clear that Socrates often has actions and consequences in mind, but he does not depict the weak man's knowledge (or the science of measurement) in these terms exclusively. Instead, the relevant knowledge is put in general terms. For instance, 355a6, and 355c2, and throughout the argument, Socrates attributes to the weak man

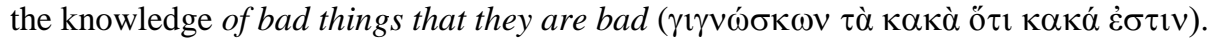


(356b), however, that the phenomenon of being overcome by pleasure is explained by reference to the power of appearance, so that the weak man performs $\phi$ because he is swayed by the power of appearance. Moreover, Socrates has informed the Many that the power of appearance is deceptive - that it causes confusion by making the nearer pleasure seem greater than it really is. And the only antidote to this illusion is the science of measurement, which enables one to place pleasurable things and painful things into the same scale together, regardless of temporal distance. This technique procures expert knowledge ( $\dot{\varepsilon} \pi \imath \tau \eta \dot{\mu \eta})$ of the relative value of things. In other words, the science of measurement procures knowledge of bad things that they are bad, of good things that they are good. And, as the only antidote to the power of appearance, Socrates declares this "our salvation in life."

The term 'salvation' ( $\sigma \omega \tau \eta \rho i ́ \alpha)$ plays an interesting role in Socrates' demonstration. At $356 \mathrm{~d}$, it is simply equated with the science of measurement— Socrates says that the science of

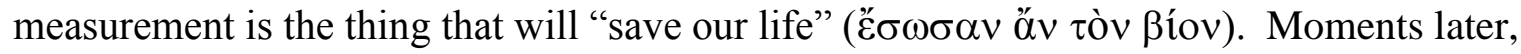
however, Socrates elaborates. Here, at 357a, the actual correct choice of pleasure and pain is our salvation ( $\sigma \omega \tau \eta \rho i ́ \alpha)$. In other words, our salvation consists not just in the possession of the science of measurement, but in our choosing to act in accordance with its results. These two conditions, then—possession and application—appear to be necessary, and jointly sufficient for our salvation. Thus, Socrates proceeds to pose the following question. "Since our salvation in life has turned out to lie in the correct choice of pleasure and pain... is it not first a question of measurement, consisting as it does in a consideration of relative excess, defect, or equality?" This is surely right.

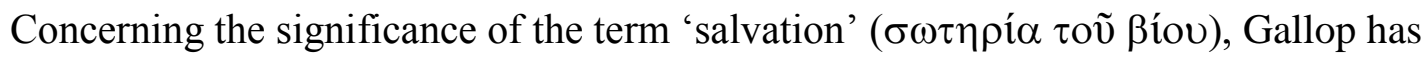
correctly noted that "salvation acts as a bridge by which the concepts of knowledge and correct 
choice can be equated." The converse holds true as well— salvation acts as a bridge connecting error with ignorance. Of course, Gallop's conclusion is that Socrates merely assumes that "if only we had such an art we should unquestionably apply it in any given situation, and act in accordance with the results it yielded." This is true, according to Gallop, because Socrates is assuming psychological hedonism $(\mathrm{PH})$. Indeed, it may seem natural to import $(\mathrm{PH})$, or to assume that Socrates simply ignores the possibility that an agent could possess the relevant knowledge, but choose not to apply it. In fact, many commentators have drawn this conclusion. After all, if we import psychological hedonism into the argument, then we will be equipped to explain how the bridge works, and to draw Gallop's conclusion that $(\mathrm{Eb})$ entails the denial of $\left(\mathrm{Ea}^{*}\right)$. Unfortunately, however, we have encountered good reasons for thinking the $(\mathrm{PH})$ does not factor into the demonstration. So let us re-examine the entailment that the epistemic interpretation must establish. The entailment of ignorance from error can be expressed by the following conditional:

If a man performs a bad action $\phi$ willingly because he is overcome by pleasures $(\mathrm{Eb})$, then he does not know of bad things that they are bad (not-Ea*).

Or, given Socrates' assessment of what being overcome by pleasure really amounts to, the entailment becomes:

If a man performs a bad action $\phi$ willingly because he is swayed by the power of appearance (Eb), then he does not know of bad things that they are bad (not-Ea*).

This conditional must be established by the epistemic interpretation in one way or another. And I am in agreement with Gallop that the concept of salvation acts as a bridge connecting the antecedent with the consequent. But perhaps the inclusion of $(\mathrm{PH})$ is unnecessary here. Let me explain. There appear to be two possible scenarios capable of producing the weak man's error 
(Eb). First, supposing the weak man is swayed by the power of appearance because he lacks the science of measurement, what he lacks is knowledge, and his error is the result of ignorance. This much is clear. But let us briefly consider the other possibility; the possibility Socrates supposedly ignores; the possibility that an agent might possess the science of measurement but choose not to apply its results. In this scenario, the agent might be said to yield to the power of appearance even though she possesses the antidote. Perhaps she even performs the necessary calculations, placing both pleasurable and painful consequences together into the same scale in order to determine that $\phi$ is a bad action. But she ultimately disregards her results and chooses to act contrary to her science. She knows that $\phi$ is a bad action, yet she performs $\phi$ willingly and knowingly nevertheless. In order to establish the relevant conditional, this scenario must be explained away. $^{21}$

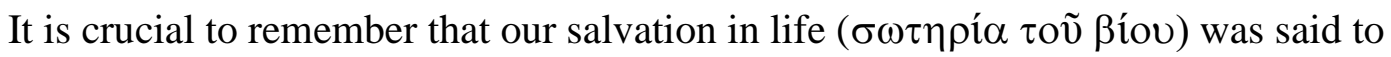
consist not merely in the possession of this science, but also in its application. Salvation was said to consist in correct choice. As a result, the agent who disregards her science has thereby failed to save her own life. At this point, an important question arises. What does it mean for

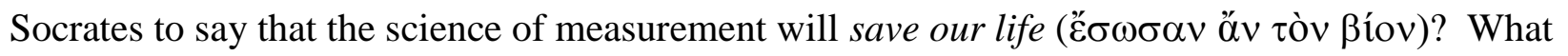
will it save us from? Surprisingly, commentators have ignored this question completely, perhaps because it is not explicitly answered in our text. As far as I can tell, however, this question is essential to understanding Socrates' argument.

\footnotetext{
${ }^{21}$ Psychological hedonism (PH) would render this scenario impossible by psychological law, thus establishing the conditional. But what happens when we don't import (PH) into the argument? Taylor (1990), who isn't convinced that $(\mathrm{PH})$ factors into the argument against the Many, concludes that the argument is based on fallacy, since it overlooks the possibility that one might possess, but not apply, their knowledge. For Taylor (1990), Socrates proves only that if one chooses correctly, then one possesses the science of measurement. But Socrates conclusion is our conditional if one does not choose correctly, then one does not possess the science of measurement. Thus, as Klosko (1980) later put it, "Taylor objects to this conclusion as established through the simple fallacy of denying the antecedent (p.318)." As I will argue, however, Socrates' use of "salvation" may provide a way out of this accusation.
} 
The most natural answer is that the science of measurement will save us from a bad life.

It will save us from a life that is not worth living. Consider, for instance, Socrates' language at

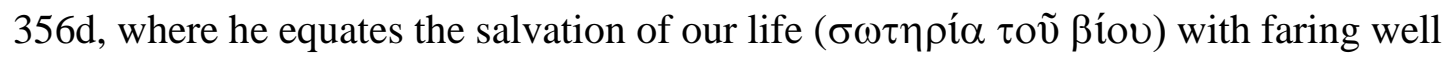

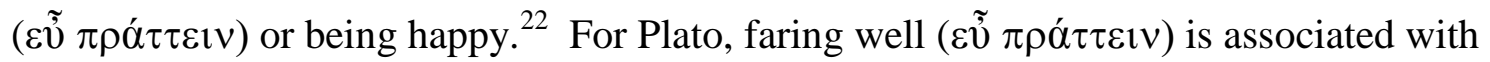

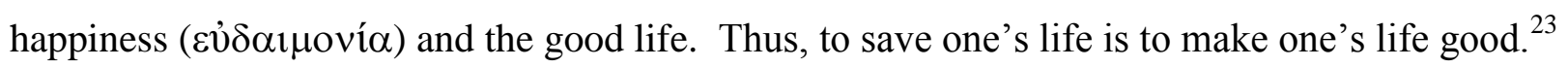

But we should notice that Socrates' language here is suggestive of an all-or-nothing affair — the agent's entire life depends on their choice. One commentator writes that "Socrates' emphasis on saving one's life is deliberate... [Socrates] says that, if one's life depended on [...] making correct judgments and choices based on them, one would not be able to rely on observation of how things look etc., but would require a technique of measurement."24 I would add, moreover, that the use of salvation makes it perfectly clear that (at least on the assumption of hedonism) our life does depend on this technique. In particular, it is essential to Socrates' demonstration that, without the application of this technique, our lives will go bad. This adds depth to Socrates'

22 356d: "If our faring well ( $\dot{\eta} \mu \overline{\mathrm{i}} v \tilde{\eta} v \varepsilon \tilde{\tilde{u}} \pi \rho \alpha ́ \tau \tau \varepsilon 1 v)$ had depended on taking steps to get large quantities, and avoid small ones, what should we have judged to be the salvation of our lives ( $\dot{\eta} \mu \bar{\imath} v \sigma \omega \tau \eta \rho i ́ \alpha ~ \tau o \bar{v} \beta$ íov)?" Here, as I see it, the salvation of our lives (i.e. the science of measurement) is what secures the good life ( $\varepsilon \tilde{v} \pi \rho \alpha ́ \tau \tau \varepsilon ı v)$. And if we do not save our life, then our life will go bad. Compare, for instance, Socrates' language in the Crito (47e-48a). "What about the part of us which is damaged by wrong actions and benefited by right ones? Is life worth living with this part ruined? Certainly not...At the same time, I should like you to consider whether we are still satisfied on this point, that the really important thing is not to live, but to live well ( $\tau$ ò $\varepsilon \tilde{u} \zeta \tilde{\eta} v) . "$

${ }^{23}$ See Charmides 171e7: "With error abolished, and correctness guiding, men in that condition [i.e. who possess

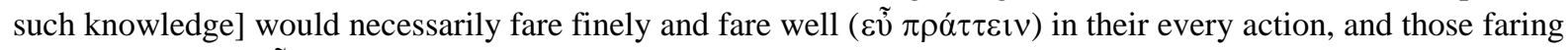

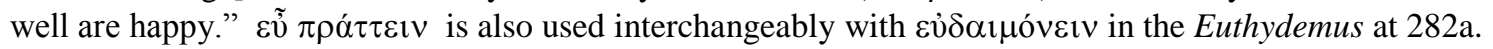

${ }^{24}$ See Taylor $(1990,191)$. Taylor writes concerning this argument that it simply "ignores the distinction between being regularly right and being right on every occasion which Socrates' exposition requires." We might wonder why

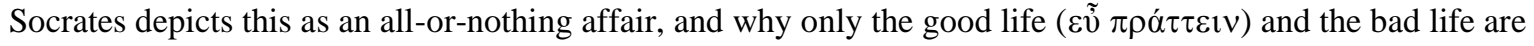
represented here (i.e. why no intermediary lives). Regardless, it is clear according to Socrates, that the agent's entire life will be determined by their correct choice. From Socrates' argument, we get the distinct sense that the agent's life is at stake. 
argument by introducing relative values, not just of actions and consequence, but of lives as a whole ( $\tau$ oṽ $\beta$ íou). ${ }^{25}$

Let us now return to our agent who chooses not to apply her science. If indeed the application of the science of measurement is the only thing that will save us from a bad life, then the agent who chooses not to apply her science will have successfully ruined her own life. Of course, it goes without saying that she wanted to fare well and be happy. This is the core or Greek eudaemonism — that all human beings desire their own happiness, and that happiness is

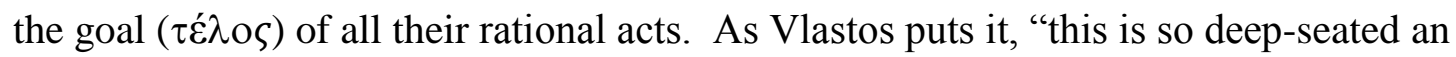
assumption that it is simply taken for granted: no argument is ever given for it in the Platonic corpus." ${ }^{26}$ All men desire to fare well. In fact, faring well is the decisive consideration of human action. In the Euthydemus, Socrates states this assumption most emphatically:

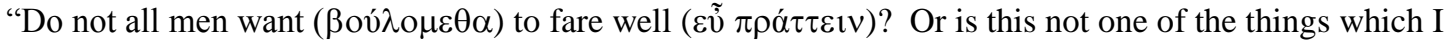
feared a moment ago it would be ridiculous ( $\kappa \alpha \tau \alpha \gamma \varepsilon \lambda \alpha \dot{\sigma} \sigma \tau \omega$ ) to question? For surely it is silly to ask such a question. For which man does not want to fare well?"

Euthy 278e
}

Since our agent's primary desire is for the enjoyment of a good life (عṽ $\pi \rho \alpha ́ \tau \tau \varepsilon \imath v)$, we might wonder why she has chosen not to apply the science that would have secured it. ${ }^{27}$

25 Vlastos (1969) makes an interesting terminological point concerning our passage. He notes that "good" and "bad" and their comparative and superlative forms "are used in the debate to express both first-order and secondorder valuations, without any alternative expressions or any auxiliary linguistic devices to mark off the differences." According to Vlastos, Socrates is sometimes speaking of the goodness or badness of actions, which is a secondorder valuation that consists of weighing good and bad consequences (the first-order valuations). By focusing on Socrates' use of "salvation of one's life," my interpretation actually locates an additional layer of complexity. The

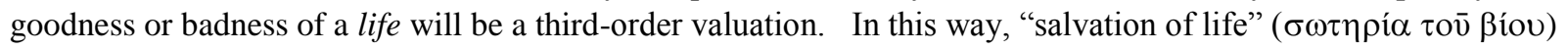
serves as a value-term associated with the good life, much like $\alpha \xi \iota \omega v$ was used previously as a value-term associated with good consequences/actions. See Vlastos (1969).

26 Vlastos, (1985), pp.3-22 (footnote 14).

${ }^{27}$ Let me respond to any potential objection having to do with my equating the "good life" with the notion of faring well ( $\varepsilon \tilde{\tilde{u}} \pi \rho \alpha \dot{\tau} \tau \tau \varepsilon v)$ ). Socrates has already connected faring well with the salvation of one's life (356d), which causes us to interpret the notion of faring well in terms of life as a whole. But, I will also quote from Bobonich (2011), who has written recently concerning the common, non-philosophical notion of happiness that would have been prevalent 
At this point, it should become clear that the epistemic interpretation can succeed without importing psychological hedonism $(\mathrm{PH})$ into the demonstration. Given Plato's frequent emphasis on "saving one's life," a much weaker principle will do the trick. I suspect that Plato is merely assuming that no one would knowingly ruin their own life. It is reasonable to think that anyone who disregards her science, precisely when her life depends on it, simply does not know that her life depends on it. ${ }^{28}$ In other words, perhaps Plato is assuming a version of psychological eudaemonism.

(PE) Necessarily, men only choose actions they believe to be consistent with their own

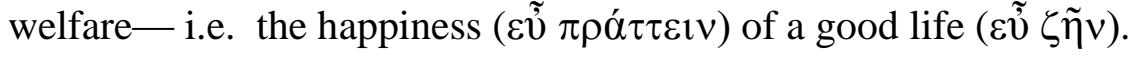

According to (PE), it would be impossible for a human being to knowingly or willingly ruin their own life. Thus, regarding the agent who possesses but chooses not apply her science, the only remaining explanation is that the agent does not know that her life depends on her correct choice concerning $\phi$. Perhaps she understands (in some sense) that $\phi$ is a bad action when she chooses to perform $\phi$, but she doesn't fully appreciate the impact her choice will have on her life as a whole. In other words, she does not know that she is making a bad life for herself. Needless to say, this would constitute an intellectual error-a species of ignorance. But here's the most

among the Many. He writes that "two central lines of thought [were] already implicit in early non-philosophical claims about happiness that are especially important for the later Greek philosophical tradition [i.e. Socrates, Plato,

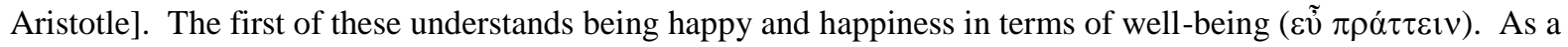
first approximation, let us say that a person is happy or attains happiness if and only if he lives a life that is best for him, all things considered." The version of psychological eudaemonism I propose above (PE) is slightly weaker. It requires only that the agent act consistently with what they see as a good life, not necessarily with the optimally best life. See Bobonich, (2011), p.295.

${ }^{28}$ Compare Aristotle, in Book III of Nichomachean Ethics. There, he discusses the nature of voluntary and involuntary acts. He briefly considers a borderline case of voluntary action in which the agent must throw cargo overboard in a storm in order to "save his life ( $\sigma \omega \tau \eta \rho i ́ \alpha)$." Aristotle comments that "anyone having a mind"

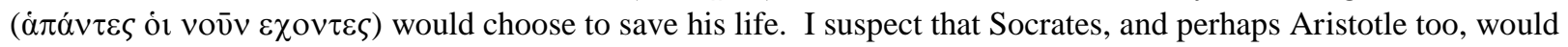
classify the agent who chooses to go down with his cargo - or by analogy here, to go down with the immediate pleasure - thus failing to save his own life, as ignorant of the relative values of the actions available to him. Perhaps they would even call this "the greatest ignorance," see $357 \mathrm{e}$. 
crucial point. If an agent does not know of the life that she is making that it is a bad life, then she cannot be said to know of bad things that they are bad. And this is the denial of (Ea*). As it turns out, then, the agent cannot be said to possess the science of measurement. ${ }^{29}$ And so, the required entailment has been established by means of psychological eudaemonism (PE); for the failure to apply the science of measurement simply collapses into a failure to possess it. And, in this way, we come to agree with Gallop's claim.

"when Socrates claims that we should be saved by the art of measurement, he is assuming that if only we had such an art we should unquestionably apply it in any given situation, and act in accordance with the results it yielded."

But we arrive at this agreement by means of psychological eudaemonism (PE), which is distinct from psychological hedonism $(\mathrm{PH})$. According to psychological hedonism $(\mathrm{PH})$, one must always choose the action they think most pleasant. In contrast, according to eudaemonism (PE), one is capable of choosing the less pleasant option (overall), but only under special circumstances - only under circumstances in which the agent underestimates the impact this will have on her life as a whole. Thus, an agent can perform a bad action, while thinking that it is bad, only if they do not understand that (by doing so) they are making a bad life for themselves. In this sense, eudaemonism (PE) is much weaker than psychological hedonism (PH). Yet eudaemonism (PE) is perfectly capable of explaining how (Eb) entails the denial of (Ea*).

\footnotetext{
${ }^{29}$ After all, the science of measurement procures knowledge of bad things that they are bad, and of good things that they are good. In other words, it is possible that a weak agent might underestimate the impact her choice will have on the value of her life. By choosing a bad action $\phi$, she may not know that she is making a bad life for herself. But, then, she certainly does not know of bad things that they are bad. Furthermore, since she fails to see how $\phi$ affects her life as a whole, we cannot attribute to her the expert knowledge that $\phi$ is a bad action. Expert knowledge of good and bad will include an understanding of how an action stands in relation to the good life. Thus, it is clear that she does not possess the science of measurement.
} 
Moreover, it allows us to identify what is distinctive about the weak man's state of mind. He, unlike the expert, does not understand that his life depends on each and every choice he makes. ${ }^{30}$

One problem, however, is that psychological eudaemonism $(\mathrm{PE})$ is never explicitly stated within the argument. That being said, let us look very closely at what is stated. We have already

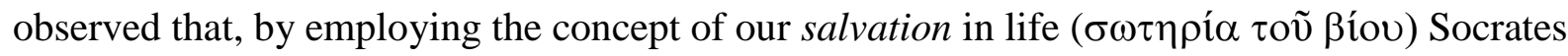
has introduced additional valuations not just of actions and consequences, but of lives as a whole. The only other claim Socrates makes about life as a whole (within our argument) occurs immediately after his bold statement that "the entire demonstration depends" on a single point (355a).
"It isn't easy to explain the real meaning of what you call being overcome by pleasure, and any demonstration is bound up in this point. It is still possible, even now, to retract a step, if in some way you can state that the good is something other than the pleasant, or that the bad is something other than the

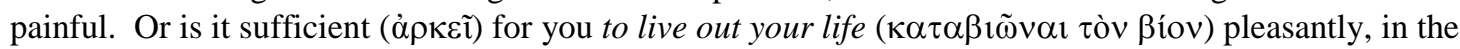 absence of pain? If it is enough, and you can't state that the good or the bad is anything other than that which does not end in these, then listen to what comes next. For this being the case, your explanation becomes ridiculous." (355a)

Here, Socrates claims that the demonstration depends on whether it is sufficient ( $\dot{\alpha} \rho \kappa \varepsilon \tilde{\imath})$ for the people to live out their lives ( $\tau$ òv ßíov) pleasurably, in the absence of pain. But sufficient for what? Apparently, Socrates thinks he must determine (for his demonstration) whether the people will get what they want out of life if they (merely) live pleasantly. Of course, the people ultimately want to fare well ( $\varepsilon \tilde{\tilde{v}} \pi \rho \alpha ́ \tau \tau \varepsilon ı v)$ and be happy. And so, Socrates is asking whether a life of pleasure is sufficient for a good and happy life. This passage echoes the question Socrates

\footnotetext{
${ }^{30}$ Concerning Socrates' argument as a whole, one defect seems to emerge from the present reading. The argument ignores an important distinction. As Taylor (1990) has already observed, the argument "ignores the distinction between being regularly right, and being right on every occasion, which Socrates' exposition requires. (p. 192)" Socrates seems to be suggesting that the good life (salvation) requires one to be right on every occasion. (Perhaps, however, this sense of urgency is precisely what wisdom requires. Socrates himself notoriously lived as if his life depended upon each and every action he performed).
} 
had previously posed to Protagoras concerning pleasure (351b) in the opening lines of our discussion.

“ Do you say, Protagoras," I said, "that some human beings live well ( $\varepsilon \tilde{u} \zeta \tilde{\eta} v)$, others badly?” He said he did. "Is it your opinion then that a human being would live well ( $\varepsilon \tilde{\tilde{v}} \zeta \tilde{\eta} v)$ if he should live with distress and pain?" He said no. "And what if he should come to the end having lived out his life ( $\tau$ ov Biov) pleasantly? Isn't it your opinion that he would have thus lived well (

But why would an answer to this question be essential to Socrates' demonstration? Why would Socrates say that the whole demonstration depends on this, for instance, rather than one of the passages often used in support of $(\mathrm{PH})$ ? Perhaps Plato is insinuating that the good life somehow matters to the argument. In order to determine what the people actually pursue, Socrates must determine what they consider the good life to be. In other words, Socrates is assuming that whatever one pursues, one ultimately pursues for the sake of a good and happy life. Perhaps this falls short of an explicit statement of (PE). But it does confirm that something sufficiently like $(\mathrm{PE})$ is operative.

Finally, it is worth noting that, if psychological hedonism $(\mathrm{PH})$ were operative instead of (PE), an answer to this question would not be important at all. For, in that case, a refutation of (E) would require no reference to life as a whole, to faring well ( $\varepsilon \tilde{v} \pi \rho \alpha ́ \tau \tau \varepsilon \imath v)$, or to being happy. In a similar way, we have seen Socrates use the notion of one's "salvation in life" as a bridge connecting ignorance and error. But again, if $(\mathrm{PH})$ were indeed operative in Socrates' demonstration, the bridge would not be necessary. Psychological hedonism (PH) conjoins ignorance and error (correct choice and knowledge) automatically, quite independently of the notion of salvation. ${ }^{31}$ If $(\mathrm{PH})$ were operative, the notion of salvation would not have been

\footnotetext{
${ }^{31}$ This is my chief criticism of Gallop (1964), who admits that the concept of salvation acts as a bridge connecting knowledge with correct choice, but simply does not explain how this works. Moreover, his inclusion of (PH) in the argument puts the concept of salvation out of a job. Once we assume that $(\mathrm{PH})$ is operative in the argument, the ridiculousness of $(\mathrm{E})$ can be explained without the employment of such a concept.
} 
required. Thus, psychological eudaemonism (PE) appears to be the only principle capable of imbuing these details with the significance Plato has lavished on them. Although I do not wish to argue the point here, I believe (PE) offers a much better analysis of the strength of knowledge (KS) as well. ${ }^{32}$ In the meantime, let me simply state that each of these considerations against $(\mathrm{PH})$ are symptoms of the same basic defect. As a premise in the argument against $(\mathrm{E}),(\mathrm{PH})$ is simply too strong. Commentators have invoked $(\mathrm{PH})$ to explain how Socrates' argument works, but $(\mathrm{PH})$ actually spoils the mechanics of the demonstration at every turn. ${ }^{33}$

\footnotetext{
${ }^{32}$ Two separate notions of strength have occupied the literature - an economic notion and a diachronic notion. Socrates initially inquires into Protagoras' view of knowledge (at 352c) with the question, “...do you think that ... if someone knows what is good and what is bad, he will never be conquered by anything so as to do otherwise than knowledge bids him?" (The answer is affirmative). This has been referred to as the economic strength of knowledge (one who knows will always act upon their knowledge, even if other psychological factors happen to be present). The notion of diachronic strength is then developed after the second substitution, as Socrates introduces the science of measurement. According to Socrates, the power of appearance causes vacillation ( $\dot{\varepsilon} \pi \lambda \dot{\alpha} v \alpha)$ by making the nearer pleasure appear greater than it really is, while the science of measurement renders this appearance

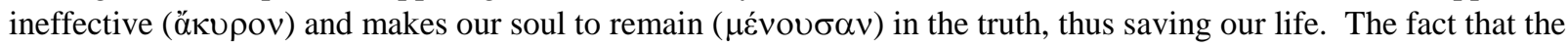
science of measurement prevents such vacillation indicates that knowledge is strong because it remains stable diachronically. It allows one to maintain "intellectual grip" on the truth as different viewpoints are presented through time. Thus, Socrates' discussion with the Many is generated by an economic notion of strength; but it ends with the diachronic notion. Both are attributed to knowledge; neither is attributed to belief. My interpretation enables knowledge to enjoy both economic and diachronic strength. According to the modified interpretation, knowledge of the value of any given action involves an understanding of how the action impacts one's life as a whole - to possess the science of measurement is to know (among other things) that the value of one's life depends

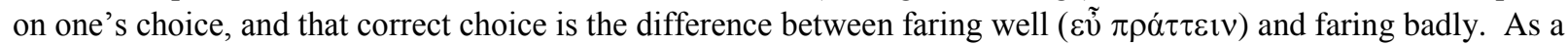
result, the agent who knows which action is best will necessarily act accordingly, since this directly engages the agent's most fundamental desire to fare well (PE). In this way, the knowledge of good and bad will always govern the actions of its possessor. Knowledge is economically strong. The modified epistemic interpretation also allows knowledge to exhibit diachronic strength. Knowledge of the goodness or badness of any given action will involve a comprehensive understanding of the good life and how that particular action stands in relation to the good life. This provides a unique perspective, which maintains a view to one's life as a whole. This is essential to Socrates' demonstration. As Taylor puts it, for Socrates, salvation requires "the ability to abstract oneself from one's actual temporal situation, so as to give one's future desires and interests equal weight or importance with one's present desires and interests (p.193)." The modified interpretation ascribes to knowledge the kind of perspective we would expect to remain diachronically stable. Socrates' demonstration to the Many is silent about the relative strength of belief.

33 Of course, a story must be told as to why the intellectualist thesis and its corollary (PH) are expressed immediately after the discussion with the Many. Protagoras had initially rejected $(\mathrm{H})$ in favor of the view that some pleasures are good, while others are bad. But after Socrates flatters the Sophists with a professional endorsement (357d-e), Protagoras readily changes his mind, and accepts (H). Having earned his trust complete, Socrates then acquires (PH) from Protagoras, which Socrates then uses to refute Protagoras' initial position regarding the virtues (that courage is different from the other virtues). Thus, (PE) is used to refute the Many, and (PH) is used to refute Protagoras.
} 


\section{BIBLIOGRAPHY}

Annas, J. 1999. Platonic Ethics Old and New, Cornell University Press.

Bobonich, C. 2010, 'Socrates and Eudaimonia' in Cambridge Companion to Socrates, Cambridge University Press, 293-332.

Davidson, D. 1980, 'How is Weakness of Will Possible?', in Essays on Actions and Events, Oxford: Oxford University Press

Deyner, N. 2008, Plato: Protagoras, Cambridge University Press.

Dyson, M. 1976, 'Knowledge and Hedonism in Plato's Protagoras', Journal of Hellenic Studies, 96.

Gallop, D. 1964, 'The Socratic Paradox in the Protagoras,' Phronesis, 9, 117-29.

Kahn, C. 1996, Plato and the Socratic Dialogue: The Philosopical Use of a Literary Form, Cambridge University Press.

Klosko, G. 1980, 'On the Analysis of Protagoras 351b-360e' Phoenix, 34, 307-22.

Penner, T. 1991, 'Desire and Power in Socrates', Apeiron, 24, 147-202.

1997, 'Socrates on the Strength of Knowledge: Protagoras 351b-357e' Archiv fur Geschichte der Philosophie, 79, 117-49.

1990, "Plato and Davidson: Parts of the Soul and Weakness of Will," in D. Copp (ed.), Canadian Philosophers. Calgary: University of Calgary Press, 35-74.

Russell, D. 2005, Plato on Pleasure and the Good Life, Oxford University Press.

Santas, G. 1966, 'Plato’s Protagoras and Explanations of Weakness,' Philosophical Review, 75, 3-33

Stokes, J. 1913, 'The Argument of Plato, Protagoras 351b-356c', Classical Quarterly, 7, 100-4.

Taylor, C. 1990, Plato: Protagoras, Oxford: Oxford University Press.

Vlastos, G. 1969, 'Socrates on Acrasia', Phoenix, 23, 71-88.

1985, 'Happiness and Virtue in Socrates' Moral Theory' Topoi 4, 3-22.

Weiss, R. 1990, 'Hedonism in the Protagoras and the Sophist's Guarantee', Ancient Philosophy, 10, 1739.

Watson, G. 1977, 'Skepticism about Weakness of Will', Philosophical Review, 86, 316-339.

Wolfsdorf, D. 2006, ' The Ridiculousness of Being Overcome by Pleasure: Protagoras 352b1-358d4', Oxford Studies in Ancient Philosophy 31:113-36 